\author{
Gerald Nestler \\ Artist and independent researcher, Austria
}

\title{
Christian Kloeckner
}

University of Bonn, Germany

\section{Stefanie Mueller}

Goethe University Frankfurt, Germany

\begin{abstract}
The work of the artist and writer Gerald Nestler explores finance and its social implications since the mid-1990s. Based on his professional experience as a trader as well as on postdisciplinary research, he has developed a unique approach that brings together theory and conversation with installation, video, performance, text, and other art forms. Probing into the narrative structures of contemporary capitalism, Nestler offers a techno-political critique directly from the core of the financial markets. This interview addresses his reading of the derivative as a world-producing apparatus that shapes the experience of the present by preconfiguring the future, and that provokes a shift from representational to performative speech in the actualization of biopower based on the exploitation of volatility and leverage. In conversation with Christian Kloeckner and Stefanie Mueller, he argues for the formation of specific human/non-human alliances that directly attack algorithmic as well as socioeconomic black-boxing (schemes that monopolize inherently non-scarce resources), so as to open our imagination to skills and tactics that would allow us to navigate the rich but volatile flows of social, political, and economic abundance.
\end{abstract}

\section{Keywords}

Art, resolution, renegade, derivatives, volatility, leverage

A graduate of the Academy of Fine Arts Vienna, Gerald Nestler worked as a broker and trader in the 1990s. The experience had a formative impact on his critical thought and art practice,

\section{Corresponding author:}

Gerald Nestler, Neulinggasse 9, 1030 Vienna, Austria. Email: mail@geraldnestler.net

http://www. geraldnestler.net 
enabling him to emerge as a rare figure in the contemporary art world, combining a technical understanding of the markets with an ability to engage across the disciplines with leading critics and theorists of contemporary finance, as well as a commitment to shaping and challenging this discourse through artistic practice. Nestler has exhibited his work internationally and received numerous grants and awards, most recently a residency at New York's International Studio and Curatorial Program (ISCP), where he collaborated with the artist Sylvia Eckermann and the high-frequency trading whistleblower Haim Bodek to create a performative mapping of automated financial markets and algorithmic perception. In 2017, he received a practice-based $\mathrm{PhD}$ from the Centre for Research Architecture at Goldsmiths, University of London. His publications include: Yx - Fluid Taxonomies - Enlitened Elevation Voided Dimensions - Human Derivatives - Vibrations in Hyperreal Econociety (Nestler, 2007), the edited collection Making of Finance (Avanessian and Nestler, 2015), a special issue on 'Art and finance' in this journal (Nestler and Malik, 2016), and an essay on the topic in the Routledge Handbook to Critical Finance Studies (Borch and Wosnitzer, forthcoming).

Stefanie Mueller (SM)/Christian Kloeckner (CK): Gerald, your artistic practice and critical writing have for a long time engaged the logic of finance and how it interacts with our broader social reality. Let's begin this conversation by talking about how you got into this, and what you mean by the term 'human derivative', which seems to be central to your thinking and your art.

Gerald Nestler (GN): I first developed this term around 2004/05 when I began to theoretically systematize my artistic practice, which was based on my stint as a broker and a trader in the 1990s. It derives from what was first my instinct, or intuition, that with the introduction of the market ideology into politics and society, the world of derivatives has come to function as a sort of processual blueprint for relations and relationships in general. Concerning terminology, however, I prefer 'derivative condition'. The term 'human' is ambiguous and, contrary to my approach, might seem to exclude non-human agents.

It might make sense here to track back a little. I was actually trained as a painter and graduated from the Academy of Fine Arts Vienna in 1992. But I spent my last year as a student delving into the 'newly hatched' Internet, which then seemed to hold potential for all kinds of new artistic practices. However, it quickly became clear that the Internet would become a much vaster and deeper social phenomenon, reaching far beyond scientific and artistic uses. I wondered if artists wouldn't have to engage with the economy - and the market especially - in order to get a grasp on the actual powers that today shape societies and subjectivities. Due to my background, I had no clue about most anything relating to the field (like most people in the art scene then), and I therefore felt an urgency to take up research. As an artist, my interest was more in the practice of finance rather than academic economics. I wasn't interested in the theory so much as what it meant to act and react in this world, and also what kinds of effects this would have on me personally. I was lucky enough to get the chance to work for a trading outfit in 1994. I didn't plan to make a career out of it, I just wanted to learn, to know. And this artistic field work - or rather work experience, as I had to commit fully in order to keep the job, to stay a member of a community that wouldn't let anyone from outside observe them - turned into a formative experience. Not so much because it taught me what kind of 'animal' the market is (or what kind of animal it made of me), but because I realized how much the market had 'infected' life. That the 'market being', as a trader in an interview with Karin Knorr Cetina once remarked, was everywhere. There is a difference between a hunch and an experience, right? And to me, this was a direct experience I wouldn't have had without doing it myself. 
So, when I left the trading outfit in 1997, it was clear to me that I would work on this topic for the next couple of years, though I didn't expect it would become a lifetime engagement. I had to come to grips with quite a few things: firstly, I had to make sense of my experience; secondly, I had to engage in a wider discussion and critique of finance; and thirdly, I had to find ways to deal artistically with a power field that defied typical forms of representation and imagery. I would say it was not by default that I began to read theory covering macro- and microeconomics, financial literature, but also philosophy, sociology, and critical theory, amongst other fields. But I was dissatisfied; nothing really related to what I had experienced, or, what I felt my experience would mean if I extended it to a more general level. And that's when I started to make notes vis-à-vis my reading, later developing texts and what I would call my hypothesis and theory of which the terms 'econociety' and 'human derivative' were some of the first outcomes.

SM: What did that transition from financial practice to theory and art look like?

GN: What intrigued me most when I began learning about finance, and especially derivatives, was their heterogeneity. They appeared to be more than an awkward and elusive scheme to make money on the decline of a stock, for example. Rather, they had a quite fascinating history that included, among many other things, a shift in attitude concerning games of chance from hazardous and unproductive guesswork to scientific speculation. The question of how to deal with risk, i.e., volatility, was revolutionized, for better or for worse. Even though there were and are lots of gamblers around, the shift towards science and computation indicated to me that we are dealing with a very different animal than one might expect at first.

So when I refer to the derivative condition, I argue that developments in finance since the early 1970s have had a forming influence on the reality of relations beyond the market and the economy per se. I also suggest that concepts like financialization, immaterial labor, and debt, which were and still are circulating within critical discourse, might fall short of fully characterizing this phenomenon. We usually get interpretations and critiques based on specific fields of research. And while we can learn a lot from them, they are also restricted to the specifics of the respective discipline, which means that they turn a blind eye to aspects that are nevertheless foundational. Or, they are based on an affirmation or critique of capitalism that can often be a bit too religious in regard to its founding theories (as in 'Hayekianism' or 'Marxism'). From my experience as a trader and reader of a wide range of literature, finance was truly a meta-field born out of the input from (and being formed by) many different fields. I felt that in order to make sense of it, one had to expand one's reading beyond financial and economic papers to computer technology, computation and information theory, cybernetics, mathematics and physics, philosophy, psychology, and ethnography, as well as to many other fields. One has to take legal aspects into consideration, as we are dealing with specific forms of contracts, i.e., a complication or complexification of contractually agreed upon promises, which in this instance turn into claims. We might even need a new word that describes the epistemic framework, and this is why I introduced the term 'technowledge' to underscore both the human and non-human contributions to visualizing and solving issues and making decisions.

So, when a purely economic outlook is not sufficient, what is the perspective from which it might make the most sense to look at finance as a social field, as a field that shapes societies and subjectivities? My personal interest as an artist and activist - in the sense of working towards agency - was to understand finance and the market as a part of contemporary life, and therefore to try to locate a form of 'agency' within it. And to me it 
seemed as if derivatives were the key to understanding a new form of sociality; a mode of relationality that is increasingly treated with quantitative methods, a mathematical and technological machine that evaluates relations and that doesn't rely on past or present so much as future encounters. Simmel's critique of money's quantification of value already makes a similar argument, but the derivative condition, at least as I see it, in the context of technological revolution and the re-evaluation of state power, radicalizes and exceeds the change in social relations Simmel was referring to. This is now a regime of relations based less on values as such (qualitative aspects based on institutional or non-institutional forms of trust, for example), but on price as a quantitative and incessantly recalibrated meeting of expectations and anticipations concerning the future. Even the paradigmatic methodology, probability theory, doesn't really go back to any values of the past when applied to historic data. The notion of the past has no bearing here. These data are simply the existing pool of future expectations actualized in a former past, which are 'now' again applied to estimate another future. So we have a regime that is totally geared towards the (potential) future, whose anticipations are constantly recalibrated and manifested through pricing.

CK: And how do you understand this logic to relate to the broader social realm?

GN: When I looked at how people today are included in the system, how our society organizes education, careers, health care, how social media organize relations between people, it dawned on me that there was an analogy, even conformity, with the financial concept of the derivative. And that therefore the social contract could be described by drawing on the financial derivative, which to me implies that the former is contingent on the latter. We are witnessing and living a social contract in which a presently performed speculative engagement with a contingent future has become the rule rather than the exception. To give but one example, even the education of our children, at least in those countries that have embraced financial capitalism the most, can be interpreted in analogy with the derivative model: a set of bets on the future 'inscription' into the social fabric via usefulness and network, with time value diminishing swiftly towards 'settlement' of the obligation to perform.

These kinds of 'decision' are based on the market as the 'underlying social security' - a contingent social unconscious, a contingent social unknown - that is highly volatile and therefore prone to trading and to being traded. And on which any potential future value (the market is incomplete because of contingency) is calculated and translated into the complex mechanism of pricing. It is evaluated - or, more to the point, recalibrated - according to the optionality of the respective outcomes relative to social, financial, educational, urban, and even racial backgrounds. The derivative condition therefore describes a new bio-political hegemony enacted by the regime of competitive pricing. It not only influences the relations between 'people and market' (the liberal condition) or 'people, market and state' (the neoliberal condition), but also the relations between people who are encouraged, or rather summoned, to leave their putative comfort zone and engage in delivering their respective future potentials in the form of commodified and tradable assets. The 'random walk' has become the paradigmatic pace in almost every respect, and 'volatile equilibrium markets' are the successors to the welfare state, whose 'global' social safety net has been turned into the 'ubiquity' of a privatized security - a control industry, to use Deleuze's terminology. Contrary to all the declarations on the value of life, human or otherwise, this becomes increasingly contingent on how it proves itself on a market, i.e., how it competes in the pricing contest. This is no longer a beauty contest or a casino; it is a fight for survival, serious and fiercely competitive, concerning a variety of cultures and lifestyles, but also life forms and species. 
As Michel Feher (2009) has shown, the profit-seeking entrepreneurial spirit is turned into an appreciation-seeking speculative spirit. When I say speculation, I mean the market triangle of speculation, hedging, and arbitrage. It includes hedging one's future, and arbitrage opportunities - riskless profits, gained on a sort of 'closed-outcry market', where imitation and control are still paramount for competitive edge. Even relational or family ties and other connections are either made to pay (arbitrage) or dissolve (mainly an externality). Just think of the latest generation of social credit scores in China, and how they are beginning to turn every relation into a highly volatile asset in relation to all other individualized assets. This turns the concept of the individual from one of inalienable rights and authenticity into one of automated derivation and volatility (risk). If you have 'friends' with lower scores, your score is instantly affected. This is an extreme but very real example of the derivative condition because everyone is betting on presently anticipated future outcomes, and constantly has to recalibrate their own and their friends' 'option price'. And these systems are implemented to involve every individual in the 'game'. It is the perfect information market in which everyone is not only a sensor but also an agent - however, neither for their own good nor for a common good - but for an underlying control system that knows no value, only price.

The shift was slow enough to work subliminally. Metaphorically speaking, it resembles the urban legend in which a frog never notices it is being cooked alive because the water is very slowly brought to the boiling point. A lot of people, I would say, feel 'froggish'. We are often confused, even numb and blind vis-à-vis developments that undermine democratic accountability in favor of the evaluation regimes of market and security apparatuses. 'Securityzation' (as a power triangle of security, austerity, and asset investments) is decoupling and blacking out general assumptions on civil and political rights (and human rights too, which are rewritten around a credit system in which inalienable rights do not exist), reducing participation in political and economic affairs and decision-making. And all this is happening within a context of increasing automation of data and commodity production.

CK: Do you see any upsides to the derivative condition, or ways of making it constructive for envisioning a different future?

GN: Now, the 'good thing', so to say, is that this regime - or technology, as Elie Ayache would call it - is ultimately about relations and their potentials for generating outcomes in the future (see Ayache, 2010; 2015). More so, it is about expectations on real events (underlying and vanilla options), as well as about expectations on expectations (more complex derivatives). The question is, therefore, whether we can make derivatives and their utilization a science or practice for organizing complex societies in a fairer and more inclusive way. If they are a technology developed from scientific premises, doesn't this imply that there is a way to free them from the grip of financial capitalism or state power? Even though the alliance between capitalism and the sciences is as old as derivatives markets themselves, they might not be coessential. What I call the derivative paradigm might therefore be turned into a more open and approachable arena (a multitude of arenas) in which anticipations and expectations, necessities and desires, fears and values, could be exchanged in any way. And this fight for survival might be turned into a time-space of contingency, where we as human and nonhuman agents realize, or actualize, the contingent becoming of the future together. At least I believe it's worth putting some thought into what we could call a 'derivative poietics', although I prefer to use the term of poietics of resolution. 
CK: This reminds me of Randy Martin's (2015) argument, in the context of his pursuit of the 'social logic of the derivative', that risk is instrumental to artistic practice and actualized in improvisational movement practices such as skateboarding, surfing, or postmodern dance.

GN: Great that you mention Randy, who I was fortunate to meet and conduct a video interview with as part of my series, Portrait of a Philosophy (Nestler, 2014-15b). His premature death is really a major loss. I believe he would agree that risk has been a central category of modernity. It is therefore 'alive' in the arts, the sciences, and other fields, and not only in the economy and markets. It is said that the term was initially 'loaned' in the context of sixteenth-century commercial language from the Latin resicum, describing cliffs near a coast that constituted a danger to trading vessels of the early colonial era. Its origin is therefore within the economic sphere. However, the exposure to hazard embedded in the term is not confined to the dangerous effort to sail the seas along the coast, due to infant navigation skills or any other reason. The whole idea behind such endeavors is encapsulated in the emperor Charles V's motto, 'Plus Ultra', which defies the ancient 'Non Plus Ultra', pushing beyond the then known world and its limits at the Pillars of Hercules near the Straits of Gibraltar. This defiance of boundaries is, I would argue, the core of what constitutes modernity, which is defined by reorienting the perspective from past paradigms and eternal glory to future possibilities. It took pride in transgressing the limits of the older world not only commercially, but also philosophically and socially. I would therefore extend the notion of risk, as it seems to me implicit in many other human endeavors.

One root of this paradigm shift is certainly the humiliation by what was to become the origin of modern science: the insight that the Earth revolves around the sun and not the other way round. A further transformative event can be seen in the Lisbon earthquake on All Saint's Day in 1755, which has been identified as a major event in the disruption of Western faith in a benevolent God, introducing a profound feeling of uncertainty (with Voltaire, for example, it was proof of the absurdity of Leibniz's 'best of all possible worlds' theodicy). Enlightenment philosophers like Immanuel Kant turned to study natural instead of supernatural causes for such events. It became increasingly clear that we don't possess perfect information and that there is no deity either, at least not in any communion with humans. To cut a long story short, uncertainty entered the world, and along with it came risk. Not only as hazard but also as opportunity, as the early studies on probability by Fermat, Pascal, Huygens and others showed.

When it comes to the field I am engaged in, the arts, I would go as far as to call risk a fundamental value, at least in Western art. Since the Renaissance, and even more profoundly since Modernism and various avant-garde movements, artists have engaged in increasing revolutions of style, perception, perspective, and Weltanschauung - constant insurrections and radical changes within their own field - in which they have not only produced the respective 'results' (artworks) but also stood up for them. The whole process of being an artist is therefore to 'embody risk'. Art is not a discipline in the academic or technical sense of the term since the ancient artes were separated into ars and techne during the Renaissance. Art is a practice that is intrinsically a leap, a jump into the unknown, into an abyss. It is a perception of crisis - it often moves along 'self-introduced crises' - within which a new path is found. This is a hazard and a chance. Even if experience might lead the way, it does not suffice. It needs to go beyond experience; serendipity is sine qua non. Randy's narratives of dance or skateboarding are wonderful examples of risk-taking on a wide array of levels within, as you mention, the current 'social logic of derivatives'. Such forms of risk (at the level of play) might look rather innocuous, or even insignificant, to the outsider who might value the gamble on one's property or an entrepreneurial effort. But we shouldn't forget that as a result, new 
terrain, new perspectives, experiences, and outlooks are obtained, not only in art but also for life itself. Since the early days of modernity, art has been a social engine by which we perceive and comprehend our world, certainly not solely but in part because artists are not about averting or hedging risk so much as embodying it. In art, therefore, risk is fundamental, and in that specific instance, science, economy, and art are akin to one another and might be called the triple star of modernity, the trinity of the future god.

In the economy, and in finance especially, the embodiment of risk has been a collective effort since at least the first stock company in sixteenth-century Amsterdam. But the collective gets together in order to distribute, limit, and profit from risk. First in colonial merchandise reminiscent of the origin of the term, and subsequently in ever subtler and diverse, yet at the same time more powerful schemes. From the corporation as a non-human and immortal embodiment to the methodologies of insurance and the first derivatives, we look out over a human endeavor geared towards not embodying risk but abstracting risk towards the market and externalizing into bodies that which the market rationale rejects. (The economic notions of 'rationality' as well as 'externality' are examples of its affective power).

In a world in which every action is to be geared towards the future to render a profit, as the Austrian economist Ludwig von Mises (1949) once put it, uncertainty becomes the realm of economics par excellence. Uncertainty as the constant companion of every action has to be dealt with; it has to 'enter into negotiations'. As to my certainly limited knowledge, it was Frank Knight who in his book, Risk, Uncertainty and Profit (1921), established this negotiation by his distinction between uncertainty and risk. Knight's distinction is fundamental because while uncertainty cannot be modeled, risk can, or at least that's what Black-Scholes-Merton and other pricing models attempt with volatility calculation. According to Knight (1964: 20), “It will appear that a measurable uncertainty, or 'risk' proper [...] is so far different from an unmeasurable one that it is not in effect an uncertainty at all. We [...] restrict the term 'uncertainty' to cases of the non-quantitative type". Uncertainty cannot be quantified, but risk can. For the further development of finance, this distinction is seminal, especially in the post1971 world, and represents a climax of theoretical approximation since the term 'risk' first appeared some 500 years earlier. Contrary to risk management, my production of risk theorem argues that risk is a measure beyond knowledge methodologically applied to face uncertainty. It's sort of the 'particle mathematics' of finance. No trader faces uncertainty by sheer and adamant hazard, i.e., by direct and unchecked confrontation with uncertainty, and it only seems so because of the way the market serves as a forum in which uncertainty speaks through the voice of risk. Metaphorically speaking, risk is about pursuing a lead not of past traces but of future ones. It is sort of a quasi-forensics of future events - an enunciation of things as virtuals in the market forum. As if we could quasi-materialize a trace becoming. And the more 'risk particles' - we can now, by way of example, call them options - materialize by quantification (that is, all derivative prices traded), the less uncertainty we appear to encounter on our way forward (liquidity/price as relation), and the more we seem to know about the future's actual but 'fleeting approach' (matter/price as particle).

When communication technology, cybernetics, computation and economic modeling the Black Scholes Merton model - finally converged in the quantification of risk in 1973, it sparked a whole new industry and whole new logics of production - what we now call 'derivative finance'. There were other factors as well and in the same year: political ones like the collapse of the Bretton Woods agreement and the oil crisis; institutional ones like the founding of the Chicago Board Options Exchange; legal ones like contractual commodification and standardization, to give but a few examples. What I find interesting is how quickly the attitude towards derivatives was adjusted from condemning them as an immoral gamble on 
the economy of a country and even an unpatriotic act against a country's wealth, to embracing them as a scientifically sound method of evaluating risk, i.e. volatility, even though the techniques in question were developed in casino gambling by scientists and future finance wizards like Edward O. Thorp (on this see Thorp, 2011; Avanessian and Nestler, 2015).

But the point I would like to make here is that at least to me, what finance does - its mode or logics of production - is the production of risk. And I mean this, as mentioned above, neither in the sense of risk management nor in the rather bland criticism that it produces unattainable risks and thus eventually leads to disaster. Even if that is true, it is less a moral question than a systemic one. What I mean by the production of risk is that in information capitalism, risk is the method of separating the wheat of risk from the chaff of uncertainty; it is 'our' way of anticipating future events and potentials; and when we examine derivative markets what we see is that price substitutes value, quantification succeeds over qualification, in order to deal with expectations. While Plato favored the reading of a bird's liver killed at the spot, we take refuge in a spot market in which the future is delivered at present by what l'd like to call the 'random oracle'. If the first anticipated measure of risk is volatility and when its expectations are traded, it is obvious that there are many, as the future is unknown and outcomes have to be evaluated in price as to their likelihood. But as we all know from our own experience, one expectation leads to the next and so on. The sheer 'complexity' of derivatives - I should qualify that I'm not speaking here about the later generation of complex derivatives that use correlation copulas, and which should possibly be named differently as they don't derive directly from an underlying - can therefore be attributed to the ever-extending derivative valuations written upon each other, which are additionally evaluated by implied volatility at any further moment in order to recalibrate the whole derivative setting on the actualized price the volatile heart rate of finance, if you will.

SM: You've just raised the issue of expectation. You've also talked about human beings - as derivatives - in terms of 'a potential of expectations'. Could you elaborate on that? I was struck by this phrase because it seemed to capture an attitude towards subjectivity expressed by recent trends in technologies of the self, the 'quantified self movement', and so on.

GN: Now, if we accept that financial methods have had an impact on other social realms and even affected the individual (the so-called 'financialization' thesis), then the production of risk would have to be detected within the life of people and institutions as well. And I think it is safe to say that the neoliberal agenda and its affirmation of 'risk culture' (a term in finance for riskaffine activity) has itself produced a society of risk takers, regardless of whether risks are hedged or even detested: accepting and taking risk is the neoliberal virtue. In finance, risk sets the tone for all three major motions or applications - speculation, hedging, and arbitrage - and to go back to your example, I would think that this is also the case in the technologies of the self, in the quantification of bodily and other data, and in the quantified self-movement.

There is a future-at-present urgency in an increasing number of activities. Not only in actions (which are all about the future anyway, according to Mises) but also in caring and other still profit-free and therefore externalized activities. This urgency is all the more significant in the context of the measures of the austerity crisis, which not only empty the future as an array of possibilities but also empty the present as the actual 'place' in which the future is always born, and in which risk can be embodied. This seems to me to extend the notion of financialization to what I used to call the 'human derivative' (and which I now prefer to think of as the derivative condition, or the derivative paradigm, respectively, if we speak about the methodology). It is a conceptual approach to delineate the self-production of risk as a 
complexified promise that manifests in the competitive clashes of claims, as the array of future options of everyone's identities, or subjectivities in evolution, who in any way participate economically. The promise as a social contract is ideologically incorporated in the capitalist market as the competitive negotiation of dividual claims, and there is no human right outside the leveraged capture of consuming opportunities. This is neither linear nor flat, as the whole gamut of derivative recalibration is staged as well, for instance, in constant self-monitoring, self-tracking, and self-sensoring; in the constant re-evaluation of one's options and the debts taken to leverage them (in education as well as in career-development, for instance); in the constant institutional and self-reliant measuring of performance of potential and delivery (by one's company or university, one's peers or students) within an environment that integrates the individual derivative condition into the social protocol and dividual life-feeds of quantified surveillance, corporate (meta-individual/dividual) exchange data, data mining and big data 'evaluation' (a term we should actually substitute with pricing).
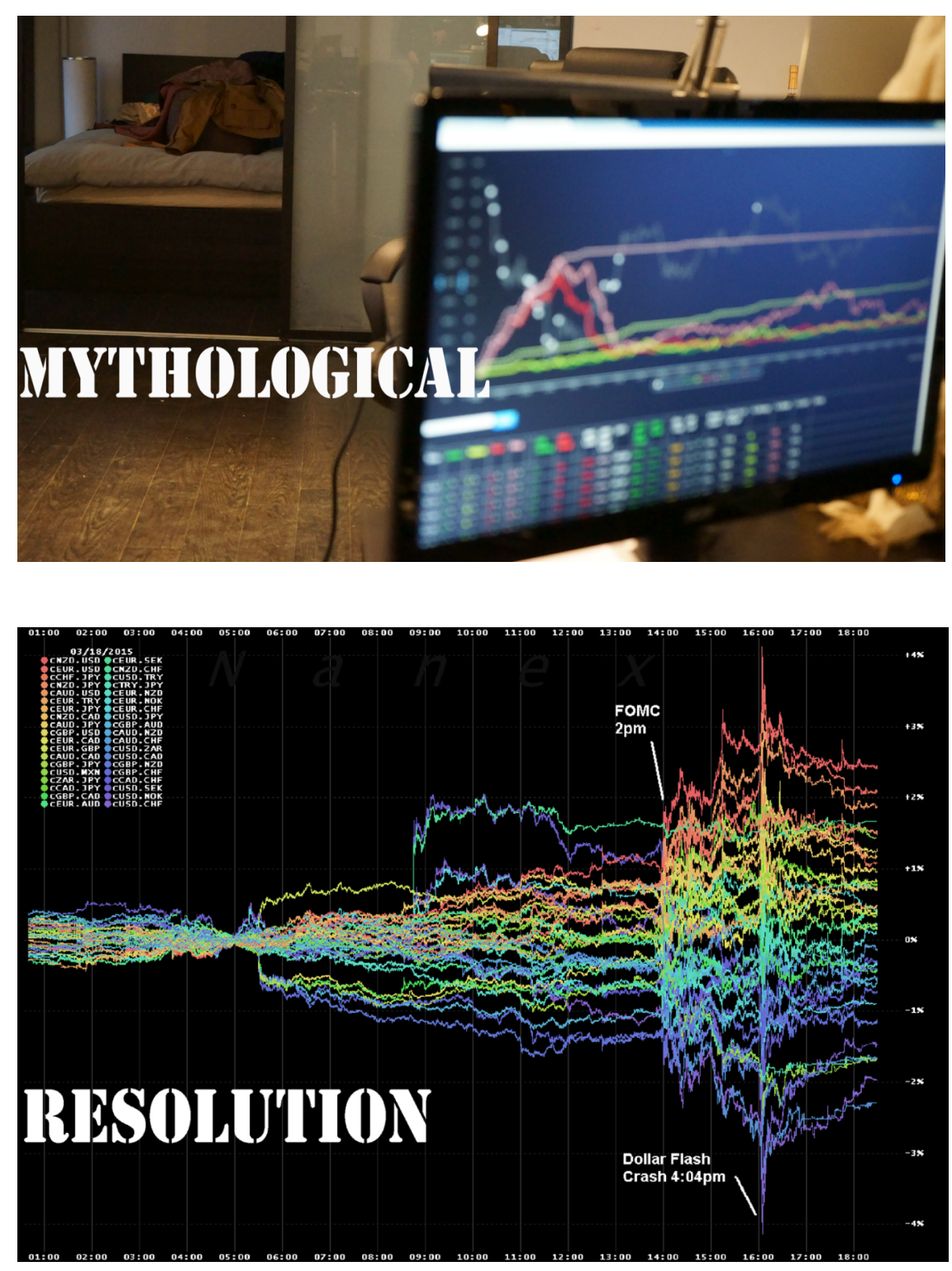

Figures 1-2. Gerald Nestler, RESOLUTIONIZATIONS: Self-organized/self-regulated/mythological, 2015. 4 prints, approx. $30 \times 50 \mathrm{~cm}$. Photographs of the hedge fund Sang Lucci and high-resolution visualizations of Flash Crashes. Courtesy and copyright of the artist/Nanex LLC. 
SM: I am interested in the question of mimesis, broadly speaking. High-frequency trading (HFT) is literally too fast for human beings to experience in actu. Your visualizations of the Flash Crash take their cue from Nanex's reconstruction, but that is a reconstruction; experience is only possible after the fact. How can art meet this challenge, the fact that it is trying to capture something that is not a human experience even in its occurrence?

GN: Your question reminds me of a statement of a trader in Marije Meerman's documentary on HFT, The Wall Street Code, who said: "What caused the Flash Crash is a nonsense question. If you were to replay the same sequence of events identically, there's no guarantee that it will cause a Flash Crash again. That's the nature of complex systems" (quoted in Meerman, 2013). That's an interesting thought, right?

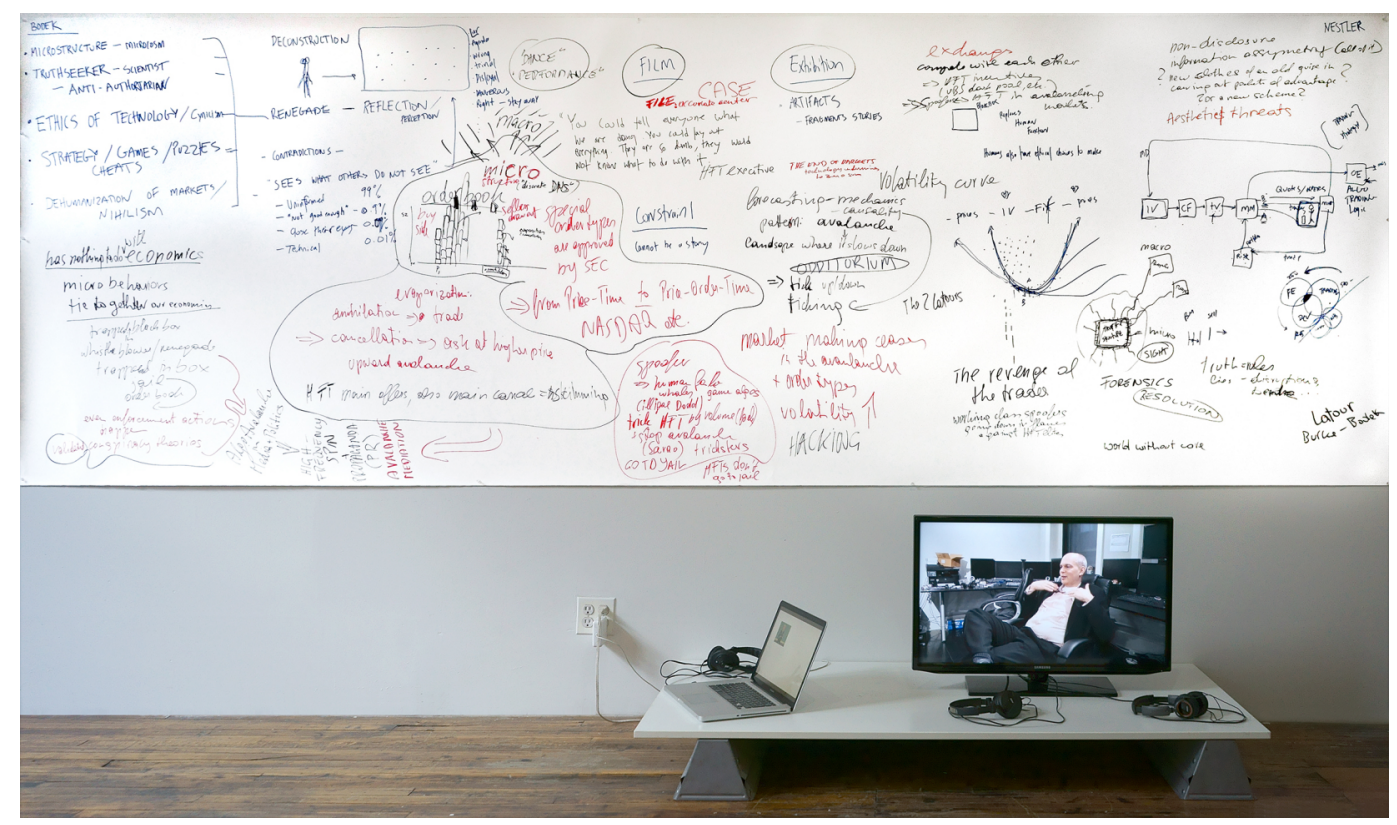

Figure 3. One of six maps of automated finance charted with Haim Bodek. Open Studio at ISCP New York, 2016. Photo: Sylvia Eckermann. See Nestler (2014-15a).

Complexity is seen as the interrelation between a large amount of players, human as well as non-human, which plays out far beyond the limits of human perception and comprehension. Replaying the entire sequence even with all its data would not be a mechanic simulation but a real-time event with all its contingencies. The market system, with its myriad of firms that use all kinds of models, technologies, and code, is more akin to Einsteinian field relativity than Newtonian physics, as Randy Martin (1990) already mentioned in his book, Performance as Political Act. At that time, market transactions still relied on human traders and took an average of 12 seconds. Now we are approaching nanoseconds, that is, 0.00000001 seconds of transaction time. Even if one trader can oversee his or her machines, the real-time interrelations of all the machines overtax both players and regulators. No wonder that the latency of the consolidated price tape (National Best Bid and Offer), a central plank in the SEC's 2005 Regulation National Market System (Reg NMS), was parasitically exploited. Speed advantage has always been 'creatively' exploited and financial markets provide an endless array of exploitable information asymmetries and arbitrage opportunities. Which certainly added to the race for speed and the race for zero margin that we have seen in the last ten 
years. However, as the HFT whistleblower Haim Bodek has observed, the algo-space became quickly deserted during the Flash Crash, and eventually human traders had to step in again (see Nestler, 2014-15a). To some degree, this means that the contest between humans and algorithms has not yet been won by the latter (an argument Elie Ayache has also made). Today, the situation has changed again, as Bodek argues, and it is often regulatory arbitrage, relating to order types for example, that makes the difference, and these schemes rely on so-called human 'collaboration' rather than automation (see Nestler et al., 2017).

What fascinated me as an artist about the Flash Crash was the fact that high-resolution does not always increase knowledge but also noise and chaos, and that the latter could well be manufactured rather than occur naturally. This revelation just jumped at me and I began to think about an aesthetics of resolution in which mimesis - to use your word - would be a performative tool, rather than a process of representation, imitation, or the like. Mimesis would not represent or imitate reality but make it happen, it would turn the time arrow around, if you like, and preconfigure the present from the future. In a way, this means to imitate the future (real) and to perform (actualize) it in the present. It would be a step too far to explain this in detail here, but more generally I think that due to the innovations in finance since the 1970s, there has been a turn in the way power speaks to us from representation to performance, and this is another reason why I speak of the derivative condition. This is a radical change for which we do not yet have the means to read. We have learned to decipher representations over the course of hundreds of years, but we lack the sensory, intellectual tools to imagine and instinctively decipher performative speech. To me, this is more likely the reason why it seems so difficult to understand the bio-politics of financial capitalism, rather than the assertion that finance is so complex and abstract. ${ }^{1}$ So I am interested in mimesis not defined as representation but as performance and, if you ask me - with reference to mimesis - how art can challenge power that we cannot perceive, one way to do this is to revert to mimesis as a physical experience. For example, I am working on a series of performance lectures (the first one in 2015 with Paul Wilmott, and more recently with Haim Bodek) that address finance performatively, both intellectually as well as physically. The body, it seems to me, is the space in which terms like volatility, leverage, speculation, and so on, reverberate very differently and more directly than when we try to make sense of them intellectually. While Haim and I speak, the audience (our underlying) encounters performers (our derivative contingent), who move through the 'crowd' in a volatile, speculative fashion, enacting in a sort of parallel universe what I would call the performative violence of finance power. They interfere with the audience's 'natural' interest in following the lecture and divert their attention. They touch and move the audience, rearrange their position, and so on. In a sense, we produce physical noise at the same time as we perform a complex representation of information. So, it is about physical interference and rupture by distracting the representative functions we apply 'automatically' as a way to support special 'senses' that allow us to decipher performative power.

More generally, I think we are at a point today at which we need to confront the narratives that shape our existence, our relations and our potentials as individuals as well as societies. If you like, one could call this a new 'realistic' art that is aware of the fact that our reality is constructed; that there are interests and contingencies at the same time; that the expert is at a loss to tell the truth; and in which reconstruction - another truth paradigm - is at a loss to relive an event. Such an art would make use of those narratives to perform its own fictions; fictions that are open and generative, but at the same time also full of interests and contingencies. We should remind ourselves that fiction is quite a powerful tool, and can be more persuasive than other forms of narration because the 'truths' it comes up with are full of 
noise and therefore aesthetically powerful. They encourage and spawn the imagination, perform mimesis on the fly to resemble a future rather than a past. While there are fictive narratives that come in the disguise of authenticity to influence (public) opinion (think about the adverse consequences of public relations, propaganda, and advertising), there is also science fiction and its narrative capabilities as an approximating trajectory to a future reality (utopian as well as dystopian). But to whatever uses all these and other tools have been aimed at, they constitute our cultural heritage and resource. They tell us about our potentials, our hopes, and our capabilities; and they remind us of the consequences of our omissions, our crimes, and the injuries we inflict on each other and the world we inhabit. So, the imagination that weaves fictions as well as the body that is exposed to forces and at the same time constitutes a relatively untapped potential of sensing, memorizing, and acting, is an interesting thing to experiment with in the face of performative power.
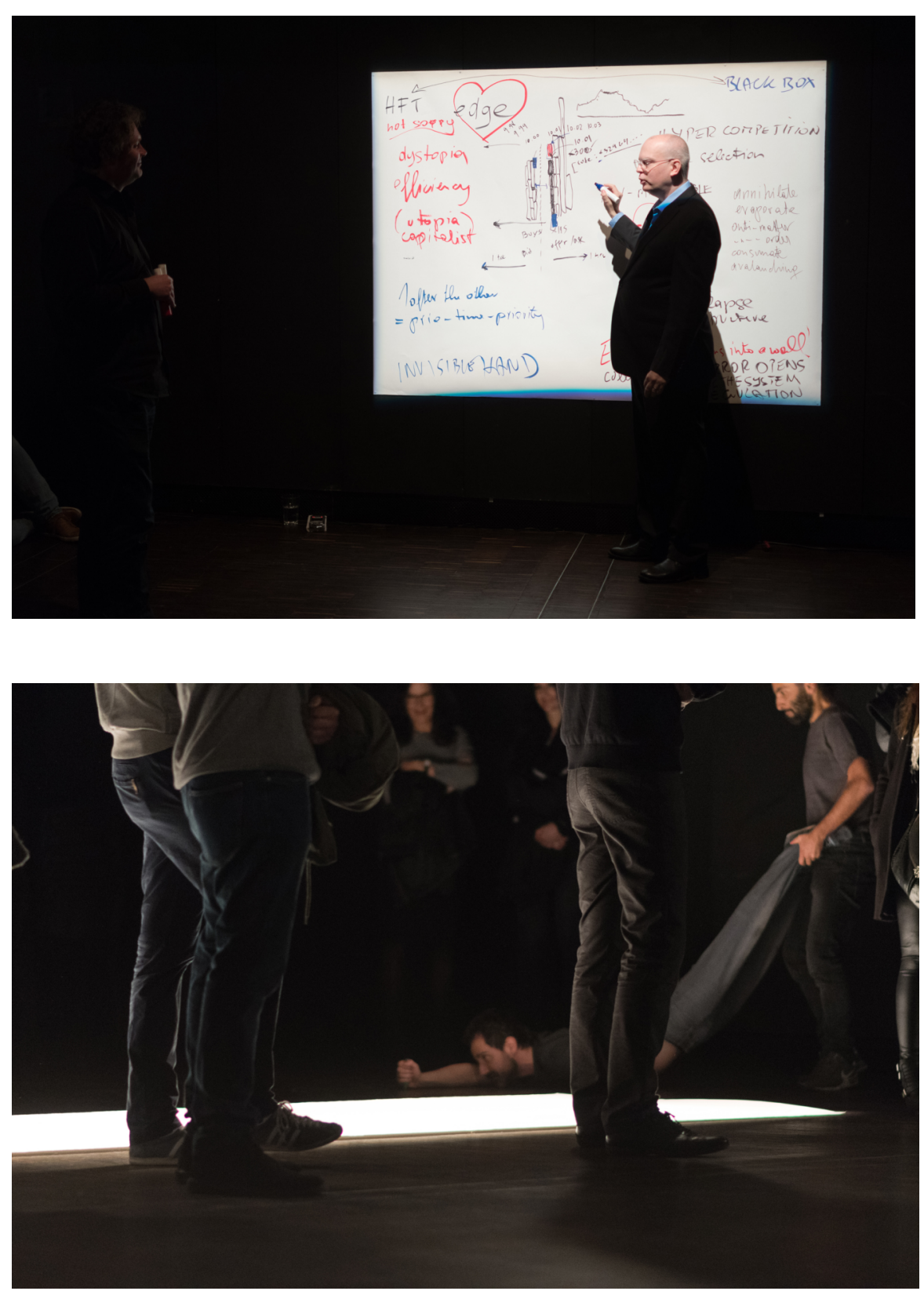

Figures 4-5. Photos from INSTANTERNITY: A Black Box Body Cult, 2017. Vorbrenner 17, Freie Theater Innsbruck, 2017. Performers: Davide De Lillis, Eva Mueller, Sebastian Collado. Photos: Christa PertI/LACHSGRAU. See Nestler et al. (2017). 
To capture something that is not a human experience is an old trick and happens not only in art. Elena Esposito once proposed to examine the novel (an artistic invention) and probability theory (a scientific one) under the same paradigm; an escape route from uncertainty that invents narratives which are 'real' enough for us to accept their reality, even though we know they are fictive (see Esposito, 2007). Both constitute parallel registers that influence our passions, our aims, and our decisions. Can we ever capture an event if not by reinventing and reconstructing it? Do algorithmic real-time decisions produce the world without human voice, and will they set up a zoo in which voice simulates culture, and will this be 'reality'? 'After the fact' and 'before the fact' might be considerations that are melting into each other and are seemingly becoming indistinguishable. Usually, science would be called to the task to investigate, discriminate, and distinguish between facts and fiction. But with Esposito, we see that this is not always possible nor is it always sensible (and we don't even mention the role of power politics and vested interests here). We therefore have to change the register and/or the regime. Essentially, art is a register- and regime-changing thing. It is therefore, at least potentially, the proper medium to relate to realities devoid of experience; either because those experiences are in the future, in a lost past, or hidden at present. In a sense, art is experience after the fact, act and matter at the same time.

One more point. Art is a practice that takes its power from the world, from the latter's huge archive of experiences and relations, from mixing in and taking out. Art is postdisciplinary because it has always been anti-disciplinary at heart. And art is out for accomplices wherever they hail from. So, what I found intriguing about Nanex, for example, was how adamantly they performatively followed the trace and the huge amount of data visualizations and analyses they published in order to make their point. I was also fascinated by the response they had in their community and how they were able to define language (think of terms like 'spoofing', 'quote stuffing', and so on). Up to this day, they are a main data and image source for flash crashes, data bursts, and other market incidents. Their financial data archive and the machines they build to sift through it constitute a very distinctive approach to a financial forensics. But while to my mind, finance as a regime has successfully turned the notion of forensis topsy-turvy by using the past as resource (data) archive of the future (a becoming by algorithmic speech), Nanex demonstrated an analysis of a past event that was scientifically sound, yet revealed at the same time how irrelevant such a reconstruction had become; and how irrelevant it is whether they are right or wrong. This kind of evidence and this kind of truth are meaningless within a proprietary black box environment; they have no purport, no relevance, as they don't relate to anything except the non-reproducible, the noncomprehensible - at least within an ideology of representation and imitation, and its legislative and executive policies. Experience is now happening before the fact; and if not, you're too late. (Even the winners are too late; they just don't see it because their affirmative performance blinds them).

SM: In this context, when you talk about an aesthetics of resolution and 'the double figure of the expert witness', you also mention the figure or position of the renegade. In how far is witnessing a renegade act in your piece?

GN: Nanex delivered data and visualizations beyond human experience. Although this is extremely unusual for the proprietary nature of finance, this is not unusual per se, as that is what enhancing resolution has been all about since at least the days of Galileo's telescope. He saw things that no one else had seen before him. Science is deeply rooted in its development in devising resolution apparatuses. In scientific studies, however, when you 'see' something 
new, you chart the traces, you describe them, you name them, and so on. In the case of Nanex's analysis of the Flash Crash, however, the traces they found could not be charted properly and given an 'address'. If you don't mind my analogy, the experimental reconstruction as 'proof of concept' of forensics led to 'castrated' evidence. They could only claim a hypothesis antithetical to the official investigation by the SEC and Commodity Futures Trading Commission and shout it out loud. There are many that disagree, but this is also true for the official report. Up to this day, at least to my knowledge, no evidence exists as to what happened exactly and we will have to see what the trial of Navinder Singh Sarao will produce.

This sparked my interest in the term resolution, and in its full semantic meaning. The term offers so much more than the technological layers of what we can perceive. It comprises visualization, cognition, knowledge-production, decision-making, (joint) determination, and majority vote. This means that the term's meanings run through the whole gamut of how a collectivity deals with issues, the contingent, the unknown. It spans across the scope of democratic legitimation. All this made it a very interesting concept for me as an artist. I would always say that art is intrinsically political. Hence, when I speak of an aesthetics of resolution, I mean a 'realism' that encompasses the whole semantic field, or, in other words, that works against those crucial nodes and sites where flows are interrupted, diverted, exploited, and voided. Every system has its resolution apparatuses - and this informs its culture - but none has ever been so successful as capitalism and (appropriated) science as its tool. Capitalism is an intricate system for directing and diverting flows; and that's what exploitation and accumulation mean. Marx's 'general intellect' comes to mind here, as does the contemporary capitalist appropriation of the sharing economy, to give but one example. Deeply intertwined with science and technology (as well as the arts when they support power), it governs inclusion and exclusion to such a degree that an outside of the system seems inconceivable today. This implies the erosion of mimesis by pure performative imitation physically, mentally, and algorithmically, and ironically sets the stage for the era after post-capitalism. I'm thinking here of Schumpeter's notions of creative destruction, of the entrepreneur (which we can also recognize today in the ideology of Silicon Valley), and his belief in the collapse of capitalism from within its elite.

One post-capitalist mark is what I call the figure of the renegade, a traitor within systems but an educator for the public. The renegade - for example, a whistleblower - is usually an expert witness who, for whatever reason, rescinds allegiance and takes counter-action. This figure is marginal (these kinds of actions rarely occur and are met with hard consequences), ambivalent (her calls are mostly about improving rather than dismantling structures and systems), and most of all fragile (because of the cascade of expert mediations necessary to make highly specialist knowledge comprehensible, not only for the public but even for the expert forum of the court, for example - and this is why I speak of a double figure of the expert witness). But at the same time, the renegade constitutes a revolutionary figure of change from within instead of from outside, as she moves from mere critique and dissent to actual forms of insurrection. And this is crucial, as it opens up new perspectives and potentials for systemic change. Ironically, the very individual and her agency take center stage at a time when such significance is deemed increasingly powerless in the eye of automation. But such a premise is less outrageous as it might seem, given that the U.S. Declaration of Independence summons everyone to act against abuse of power. Within the scope of this contextualization - the artistic creation of the narrative fiction - what seems promising is to develop a triangular relation between the aesthetics of resolution, the figure of the renegade, and a poietics of resolution that is, specific projects that make and shape resolution in the full meaning of the term: firstly, to promote open access, liability-attribution, and public scrutiny against proprietary and state 
interests; and secondly, to support and build new relations, bonds, and forms of solidarity between human and non-human agents, as well as non-agents. This might seem overambitious, but in terms of an artistic approach that focuses on consequences, it means developing narratives, imageries, and fictions that tell stories (which include but are not restricted to consequential ones), and hence produce imaginations that intensify trust that a different world is possible.

CK: In The Uprising, Franco 'Bifo' Berardi calls for a re-poeticization of our language that has become dominated by the universal exchangeability and automation of signs. According to Berardi (2012: 68), poetry's excess of sensuousness translates socially into an "insurrection of slowness, withdrawal, and exhaustion". It seems to me you're aiming for something quite different with your idea of a derivative poietics?

GN: If I understand Berardi correctly, he is aiming at a poetics in the sense of a sensitivity and imagination in relation to the body that undermines the network society and its algorithmic powers, which channel the movement (spatially, temporally, affectively) of people in a swarmlike way, through metastable governance. I have much sympathy for this attempt, but you are right, my approach of a poietics of resolution seems to differ from Berardi's poetic one.

My point of departure is that we are already living in a post-neoliberal world. Since the Lehman bankruptcy and the following bailout, we have seen enormous sums poured into the financial system, just to keep it afloat. And these programs are continuing; just think of the US and Eurozone's quantitative easing measures. Neoliberalism as an ideology in which the state is in the back seat has turned into a state-finance order. One might argue that the German version of neoliberalism, ordoliberalism, with its emphasis on the role of the nation state, has become the new paradigm with austerity programs as its corresponding politics. Socializing the losses produced by the financial system might finally mean financing consumption of those who have to bear the burden. However, it also means that the financial system doesn't work. In a nutshell, capitalism and its market system died on September 15, 2008, of apoplectic asset seizure, and since then it has been put in an artificial coma to support and monitor its life functions. Society is the derivative function of an artificially underlying 'autonomy' because the ruling ideology cannot imagine a world without capitalism. It has no clue and no desire to develop institutions that exceed neoliberal information capitalism. But due to this lethal event and its total denial, authoritarianism is emerging as an answer to the post-democratic crisis. Dissent is not a question of political attitude anymore, and so we are positively forced to think about alternative forms of resistance and make them happen.

This doesn't mean that neoliberalism was expelled from the face of the world; to the contrary, it ferociously tries to hardwire itself into memes, genes, and bytes. Coded into automated networks, exploitation and control will run beyond human intervention - including the intervention of the capitalist 'superhuman' elite. To give but one example: in analogy with the technologies of radio and television, which were initially invented as two-way systems but were quickly restricted to one-way sender-receiver media, we are today witnessing a much deeper exploitation of anything as resource by turning each 'voiceless' particle into a sensor that unconsciously communicates its metadata into automated calibration systems. Even though we might still think of the Internet as a multi-way communication system, the main bid streams run between bots and into black box proprietary systems where they are exploited without much limitation. Data prohibition, if I may call it so, foils our rights of access, narrowing down our ability to reason and to act. Legal personhood increasingly resides in the cloud and on proprietary servers, where the integrity of the legal subject is disconnected. Recoded, 
recreated, reborn as speechless voice, everything transmits and communicates - terms that are downgraded to mean facilitating mindless reactive non-mutual impulses.

I don't see how slowing down in the way Berardi proposes would help here in any substantial way. What kind of revolutionary potential would it offer? Who would it enlighten? Taken to its extreme, it sounds a bit like a work-life-balance revolt for the selected few who are still in the position to choose, and who probably live in (Western) Europe, to a lesser degree in the US, and to a still lesser degree in some pockets of Asia, the Middle East, Africa and the Americas. I don't believe in a reactionary refusal of technology (although to be clear, this is not what Berardi advocates), because we should actually be thinking about how we can use and redefine technologies. It is, for example, a well-known fact that technologies are more often than not developed in open contexts (open access, peer-to-peer, state-funded, and so on), and are exploited for proprietary interest at a later stage. Now, besides derivatives, what are the potentials of the blockchain, a distributed data and program base and public ledger technology whose peer-to-peer trust infrastructure is only just beginning to be put to use? What are the potentials of cryptocurrencies, which are already being speculatively exploited by proprietary interests? These are questions I believe are viable and crucial, and they are not in any way about slowness. I believe we need multi-speed approaches, if you like - different ways to approach things, different speeds. Molecular micro-time processes happen at a very different speed than human lovemaking or galactic supernovas. But they are all "pleasure climaxes" that we either experience or become aware of, producing a "conscious mobilization of the erotic body of the general intellect" (Berardi, 2012: 8). When I argue for a poeitics rather than for poetry, I argue for the conceptual and material realization of critique qua internal insurrection. Mind you, those people who are potential renegades are everywhere. It is not an elite or a group of radicals. It's common people, everyone who tries to make a career and a livelihood and therefore has to affirm the system. In philosophical terminology, the move from an aesthetic to a poietic (making) of resolution, and from describing to activating materials, connections, networks, registers, and properties is not a elite issue, and not even the issue of a revolutionary elite. Rather, it would be a truly precarious proletarian move, if we define the precariat as all those who do not belong to what Leslie Sklair (2001) has called the 'transnational capitalist class' and their accessories.

Basically, what I think we need to achieve is a transformation of the basic notion of capitalism: property. Unfortunately, English doesn't offer a distinction between what we call 'Besitz' and 'Eigentum' in German. But from these distinct concepts - the former legally relating to a wider concept of possession and relation, the latter distinctly attached to title and claim - capitalism was formed and interest born. Everything we possess and thus relate to, including but not at all restricted to labor, can be transferred into an asset and into a debt; German offers another double term here with 'Schuld' (guilt) and 'Schulden' (debt obligation). Today, this is encoded in a non-trivial distinction, which defines the social order of information capitalism. And I would argue, in extension of Maurizio Lazzarato (2012; 2014) and Erik Olin Wright's (2010) claims, that it is here where we can unlock the financial aspect of the contemporary class system, as it appropriates and incorporates credit evaluation (materially, relationally, and contractually). If we look at how access to capital and profit maximization is granted or denied, we quickly find two completely different registers of credit and thus appreciation schemes: debt and leverage. Debt is a credit obligation, such as a loan or a mortgage, and binds the risk-prone future of the debtor to a past she has to redeem. Leverage, however, is different, as it facilitates the class membership of those who negotiate and control the future by actively acting on and recalibrating or externalizing risk. Albeit contingent, it is the contemporary access to the 'wealth of nations' delivered by an other- 
worldliness that floats far above the commonplace of debt and austerity. I would therefore propose to deconstruct the financial class system into three 'social asset classes' that are defined by an upper class with access to leverage; a lower class burdened by debt; and a third underclass with no access to either leverage or debt, which bifurcates further into two information capitalist 'pariah classes': those who are externalized to survival mode in welfare or quasi-welfare nations, and those who are externalized into pure and irrevocable poverty.

What we need, and I believe Berardi would agree, is a fundamental change of the property regime, which nurtures the credit regime. To invoke another financial term with a much larger semantic base, we need to produce cultural and economic equity with new forms of contractual and non-contractual bonds. This would mean an appropriation of power as a performative speech for common means. And we need to find ways to make sure that these new 'bonds' will not be hijacked, as is already happening with the sharing economy and the crypto-economy. This to me defines the moment after post-capitalism. And people are developing a host of new technologies, skills, and concepts, from open-access software, to automated 3D-printing, to cryptocurrencies and the blockchain. 'Off-market' art and activism is a site of experiment with many of these things. And while the attempted outsides of "slowness, withdrawal and exhaustion" are essential recovery outings to revitalize poetic imagination and resistance, the insurrection I am interested in comes from inside the system (because that is where we all are), from its volatile jumps and information asymmetries. This upheaval takes up schemes and technologies, many of which have been hijacked before, translates and repurposes them, and plays and connects freely with temporalities. In light of the complexity and richness of the societies and cultures we live in (even though we are witnessing their destruction on a daily basis today), I'm not so sure that to 'push the delete button' on technologies like derivatives is a good idea, for example. To me the task is rather to develop ways of turning such technologies into useful tools against capitalist appropriation and the leverage class of the $1 \%$, into tools on the side of commonism. Maybe we won't need them, but I'm not so sure about that. We will have expectations and desires, there will be volatility, and we will anticipate on a more infrastructural level. People have always imaged and built tools for sharing their needs and expectations, their hopes and burdens, and the risks implied in multiple ways. Let me therefore end with a quote by Félix Guattari (2013: 1-2), written in 1989, at a moment before algorithms took off, but after the quantitative turn in finance and its first major crash in 1987:

Because machines are in a position to articulate statements and record states of fact at the rhythm of the nanosecond and, perhaps tomorrow, the picosecond does not mean that they are diabolical powers that threaten to dominate man. In fact, people are all the less justified in turning away from machines given that, after all, they are nothing other than hyperdeveloped and hyperconcentrated forms of certain aspects of human subjectivity and, let us emphasize, precisely not those aspects that polarize humans into relations of domination and power.

\section{Notes}

1. The performative speech fully arrives in fields outside finance, such as politics and media, with Mercer's investment in Brexit and the Trump presidential campaign. Donald Trump's disinterest in truth, I would argue, is based in a speculative logic. It operates performatively in the sphere of contingency. He redesigns Twitter - his dynamic hedging platform - as a Dark Pool in which the creation of waves of noise turns into competitive advantage; and escalation - that is, the production of volatility - rings in the collapse of the probability paradigm. Surfing the volatility wave, so to say, annihilates the democratic forum of discourse. Interestingly, right-wing 
reactionaries have grasped the biopower of 'fat tails' for politically exploiting information asymmetry, while the 'progressives', whose faith is still with truth (i.e., probability), are unwittingly turned into 'losers' - to use Trump's term - who cannot face up to the turn from truth to pretence. Noise is the master of information, it has replaced fact as the productive vehicle of leveraging attention power.

\section{References}

Avanessian, A. and Nestler, G. (eds.) (2015) Making of Finance, translated by J. Csuss and G. Nestler. Berlin: Merve.

Ayache, E. (2010) The Blank Swan: The End of Probability. Chichester: John Wiley \& Sons.

Ayache, E. (2015) The Medium of Contingency: An Inverse View of the Market. Houndmills: Palgrave MacMillan.

Berardi, F. (2012) The Uprising: On Poetry and Finance. Los Angeles, CA: Semiotext(e).

Borch, C. and Wosnitzer, R. (eds.) (Forthcoming) Routledge Handbook to Critical Finance Studies.

London: Routledge, in press.

Esposito, E. (2007) Die Fiktion der wahrscheinlichen Realität. Frankfurt: Suhrkamp.

Feher, M. (2009) Self-appreciation; or, the aspirations of human capital. Public Culture, 21(1): 21-41.

Guattari, F. (2013) Schizoanalytic Cartographies, translated by A. Goffey. London: Bloomsbury [1989].

Knight, F.H. (1964) Risk, Uncertainty, and Profit. New York, NY: Augustus M. Kelley [1921].

Lazzarato, M. (2012) The Making of the Indebted Man: An Essay on the Neoliberal Condition,

translated by J.D. Jordan. Los Angeles, CA: Semiotext(e).

Lazzarato, M. (2014) Signs and Machines: Capitalism and the Production of Subjectivity, translated by J.D. Jordan. Los Angeles, CA: Semiotext(e).

Martin, R. (1990) Performance as Political Act: The Embodied Self. New York, NY: Bergin \& Garvey.

Martin, R. (2015) Knowledge Ltd: Toward a Social Logic of the Derivative. Philadelphia, PA: Temple University Press.

Meerman, M. (dir.) (2013) The Wall Street Code. VPRO backlight documentary. Available at: <https://www.youtube.com/watch?v=hw3XtscVCVl>. Accessed 29 January 2018.

Nestler, G. (2007) Yx - Fluid Taxonomies - Enlitened Elevation - Voided Dimensions - Human

Derivatives - Vibrations in Hyperreal Econociety. Wien: Schlebrügge Editor.

Nestler, G. (2014-15a) CONTINGENT ETHICS. Portrait of a Philosophy Series II. Haim Bodek. 1-channel video, 44:46 minutes. Available at: <https://vimeo.com/channels/aor/127559794>. Accessed 29 January 2018.

Nestler, G. (2014-15b) CONTINGENT OPTIONALITY. Portrait of a Philosophy Series III. Randy Martin. 1channel video, 27:45 minutes. Available at: <https://vimeo.com/channels/aor>. Accessed 29 January 2018.

Nestler, G., Bodek, H. and Eckermann, S. (2017) INSTANTERNITY. A Black Box Body Cult. A Performative Mapping of Automated Finance and Algorithmic Perception. 47:30 minutes. Available soon at: <https://vimeo.com/channels/AoR>.

Nestler, G. and Malik, S. (eds.) (2016) Special issue: Art and finance. Finance and Society, 2(2): 94224.

Sklair, L. (2001) The Transnational Capitalist Class. Oxford: Blackwell.

Thorp, E.O. (2011) Putting the cards on the table: A talk with Edward O. Thorp. Journal of Investment Consulting, 12(1): 5-14.

von Mises, L. (1949) Human Action: A Treatise on Economics. New Haven, CT: Yale University Press Wright, E.O. (2010) Envisioning Real Utopias. London: Verso. 